\title{
A study of solar panel efficiency in Latvian climate conditions
}

\author{
Jevgenijs Telicko ${ }^{1,}$, Daniels Heincis ${ }^{1}$, and Andris Jakovics ${ }^{1}$ \\ ${ }^{1}$ University of Latvia, Institute of Numerical Modelling, Jelgavas 3, Riga, Latvia
}

\begin{abstract}
With solar panels increasingly used in nearly zero energy building solutions it is important to clarify if the panels can achieve the efficiency indicators specified by their producers in real operation conditions. To determine the efficiency of poly- and monocrystalline panels depending on their spatial orientation and the seasons a set of test panels was installed in 2018 in Riga, Latvia for long-term monitoring of the amount of generated power and produced energy. Here we summarize the results of the first year of monitoring. Data indicate that orientation has high significance, very small amounts of energy are generated in autumn/winter and that there is a good correspondence of the actual efficiency to the standardized estimated values. The energy production is significantly reduced by the cloudiness that is characteristic for Latvia's climate from October till January. To make a generalization of the results possible it is planned to continue the monitoring for several years.
\end{abstract}

\section{Introduction}

To reduce the greenhouse gas output into the atmosphere, renewable energy sources are considered as a solution ever more seriously [1]. Especially popular is the photovoltaic technology due to its low maintenance cost and simple installation process [2]. For nearly zero energy buildings (nZEB) solar panels could significantly reduce the energy consumption from conventional sources (i.e. electricity, steam) [3]. The efficiency of conversion from solar to electrical energy depends on the ambient temperature and decreases for higher temperatures [4]. There are two types of solar panels: mono- and polycrystalline ( $\mathrm{MC}$ and $\mathrm{PC}$, respectively). Generally, MC panels are more efficient and are superior in warm countries such as Egypt [5]. However, in a temperate climate with relatively high cloudiness, the advantages of MC panels must be studied further. Cloudiness is difficult to predict, so long-term observations are needed, but the average annual cloud cover in Riga, Latvia in 2019 was 5.91 [6]. The cloud index used in this research is derived from a meteorological station which use the traditional coefficient determination method [7].

In this manuscript we compare two types of MC and PC solar panels in a temperate Latvian climate. The panels were arranged in pairs, with different orientations (south (S), east (E) and west (W)) and at different angles with respect to the ground. Theoretically, the optimum angle for panels in Latvia is $80^{\circ}$ in winter, $57^{\circ}$ in spring/autumn, $34^{\circ}$ in summer, oriented due South [8]. The optimum angle considering the changes in the solar radiation intensity over months, calculated according to the Solar Electricity Handbook, is $39^{\circ}$ [9]. Here the energy losses of inverters, batteries and system logical components were not considered. This research work is focused on energy, produced by solar panels. Therefore, in real conditions, the final consumer will receive less energy than is produced. The purpose of this study is to determine the practical achievable efficiency of PC and MC solar panels depending on their orientation. Previous studies conducted in the Latvian climate assessed the effectiveness of panels in general [10]. Here we compare the performance of two panel types.

\section{Installations}

\subsection{System description}

The solar panel system installed at the Botanical garden, University of Latvia, contains two types of panels JAP60-275/4BB (PC) [11] and LG365Q1C-A5 (MC) [12]. Basic panel specifications are given in Table 1.

Efficiency coefficients of these panels are given per the standard test conditions (STC): $25^{\circ} \mathrm{C}$ ambient temperature, $1000 \mathrm{~W} / \mathrm{m}^{2}$ solar radiation intensity, etc.

Table 1. Specifications for PC and MC solar panels

\begin{tabular}{|l|l|l|}
\hline Abbreviation & JA & LG \\
\hline Model & JAP60-275/4BB & LG365Q1C-A5 \\
\hline Panel type & Polycrystalline & Monocrystalline \\
\hline Surface area, $\mathrm{m}^{2}$ & 1.64 & 1.72 \\
\hline Efficiency, \% & 16 & 20 \\
\hline Maximal power & 200 & 275 \\
\hline
\end{tabular}

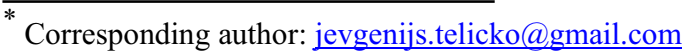


According to the reference guides provided by the manufacturers, $L G$ is expected to perform better on days with high solar intensity [12], whereas JA will perform better in an environment of lower solar intensity [11].

The panel system consists of 10 solar panels set up in five different orientations such that panels of either type, $\mathrm{MC}$ or $\mathrm{PC}$, are tested for every orientation. To be concise, we will designate a panel facing cardinal direction $\mathrm{X}$ at an angle $\mathrm{Y}$ to the horizon as $\mathrm{XY}$. There are two groups of orientations:

- E13, W13, S13

- $\mathrm{S} 40, \mathrm{~S} 90, \mathrm{~S} 13$

The orientation was chosen according to information about typical engineering solutions in Latvia received from building experts. The panels have been set up on the roofs of the buildings to reduce shading by surrounding objects such as trees (Figure 1).

\subsection{System description}

Data from the solar panels are transferred via internet connection and stored in the Victron energy database where from they are downloaded via Victron Remote Management Portal.

Data are retrieved by connecting to a remote access site which displays the data. One can download a file containing data from all sensors for a chosen time period. A computer program for automatic data downloading was created and tested and allows collecting data regularly.

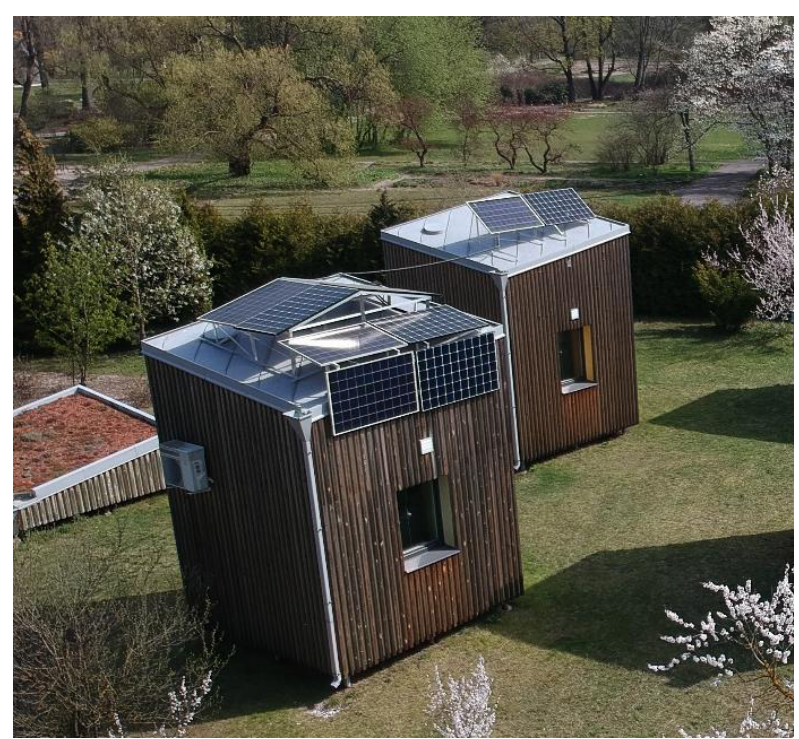

Fig. 1. The solar panel system in the Botanical garden (University of Latvia, Riga).

Ten parameters that describe the power output of the solar panels are selected, normalized by the panel surface area and used to calculate kilowatt-hours of produced energy.

Several defects in datasets were found. Registered data points were non-uniform in time. Ideally, data points should be spaced minute-by-minute, but there are cases where data points are separated by one or two seconds. Averaging the data with a minute-wide window was done to avoid artifacts during integration. There were also intervals, a few minutes long, with no recorded data. These occurred when the power output momentarily dropped to zero. If this decline was slower, it could have been explained by cloud shading. These gaps in the data also affect the accuracy of the results.

\section{Results and discussion}

We analyzed the amount of energy that solar panels can potentially produce by assessing the incidence angle of solar radiation and its intensity $\left(\mathrm{W} / \mathrm{m}^{2}\right)$. The latter depends on the season, time of day and cloud index. For example, in Figure 2a one can see the radiation intensity on a horizontal surface on different sunny winter and summer days as well as a little and very cloudy days in summer. It shows that even in the same season the solar energy accumulated can differ many times. In ideally sunny weather in June the maximum flux on the horizontal surface reaches $1250 \mathrm{~W} / \mathrm{m}^{2}$, but on a sunny day in the end of January - only $300 \mathrm{~W} / \mathrm{m}^{2}$. There is also a big difference in daylight hours between seasons. The daylight time is almost three times longer in June $(17 \mathrm{~h}$ $50 \mathrm{~min})$ than in December $(6 \mathrm{~h} 40 \mathrm{~min})$. In addition, variation in the incidence angle of solar ray during the day result in up a tenfold variation in the accumulated energy. In 2019, the received solar energy in December versus June differed by a factor of 30 (Figure 2b). Measurements of solar radiation over six years show that there are significant yearly variations differences. For instance, in April 2015 the intensity was nearly twice lower than in April 2019 due to cloudiness (Figure 2b).
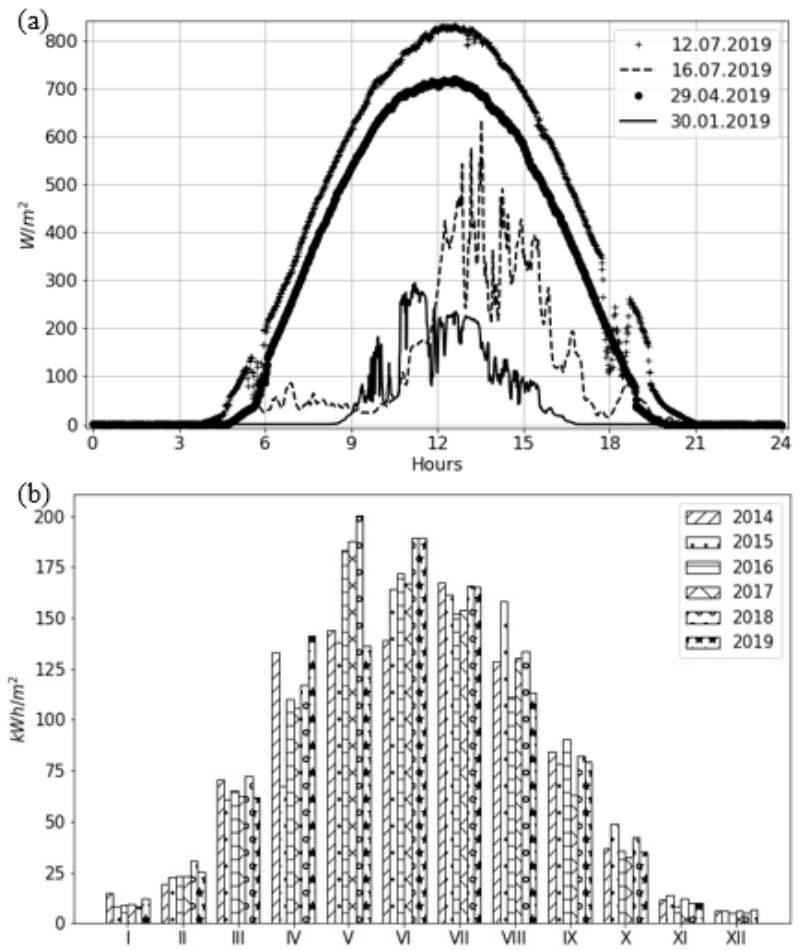

Fig. 2. (a) Solar radiation intensity over one day in different seasons and for different cloudiness and (b) the supplied solar energy to a horizontal surface over a period of six years. 
This is also observable in winter, as seen in Figure 2a. This motivates long-term monitoring to determine the actual efficiency of panels.

If the solar panels are placed vertically - for example, as a part of the southern wall construction then the amount of energy is comparable to other orientations. This, however, is only true from October to March and the rest of the year corresponds to significantly lower energy output. Especially in summer months, their efficiency can be twice lower than for better placed panels (see Figure 3a). The panels on the walls of small buildings are likely to be overshadowed by objects in the environment, further reducing the energy yield. In contrast, S40 panels produce noticeably more energy in autumn, winter and spring and generate maximum energy in summer. However, in summer months the performance of S13, E13 or W13 panels can be equivalent or better. If $\mathrm{S} 13$ panels are used as reference, comparing other orientations with the same panel type (MC or PC) to $\mathrm{S} 13$ yields up to $22 \%$ difference in produced energy for PC and up to $24 \%$ for $\mathrm{MC}$ (here the vertical panels were not considered).
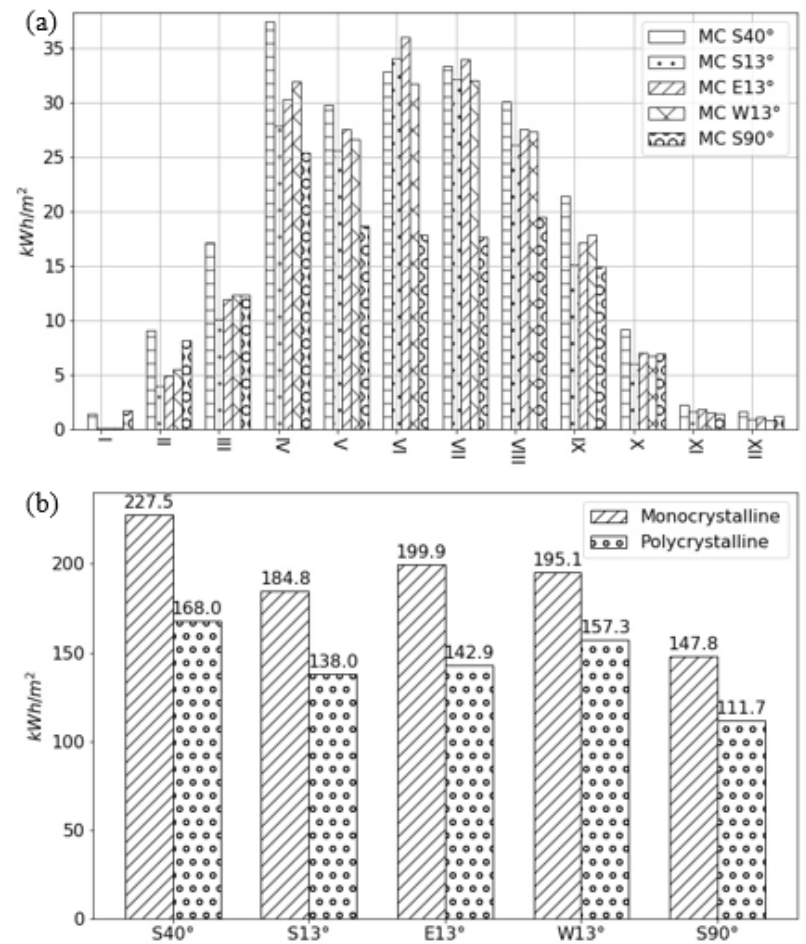

Fig. 3. Energy generated by MC panels each month by different orientations (a) and the total generated energy in 2019 by differently orientated panels (b)

However, for angles close to $0^{\circ}$ the energy production in winter can be reduced even more due to snow, as was the case in January 2019 (Figure 3a). Also, the $40^{\circ}$ solution is more appropriate for slanted roofs, while a $13^{\circ}$ orientation could be more convenient for flat roofs. From March to September ( 7 months) typically $90 \%$ of the yearly energy output is being produced. This implies that PVs can be used for powering cooling and ventilation systems in the warm season, but in winter PVs are not efficient enough to power heating systems and one should instead rely on solar collectors. During wither, there is little difference in performance of PC versus MC panels (Figure 4a shows the comparison for January). However, the energy yield in winter is too low to be considered. In contrast, in summer months (Figure 4b) MC panels can generate $30-40 \%$ more energy than PC panels. The impact panel orientation is relatively small in June as well. Again, S90 panels which generate only slightly more than $50 \%$ of the energy generated by panels with other orientations. Since most of the energy output is produced in summer, it is not surprising that MC panels generated on average 33\% more energy than PC panels (S90 orientation was not considered). Table 2 shows the comparison for different orientations. According to data for 2019 the maximum efficiency is achieved by S40 (Figure 3b). However, we would need to record data for several more years to generalize.

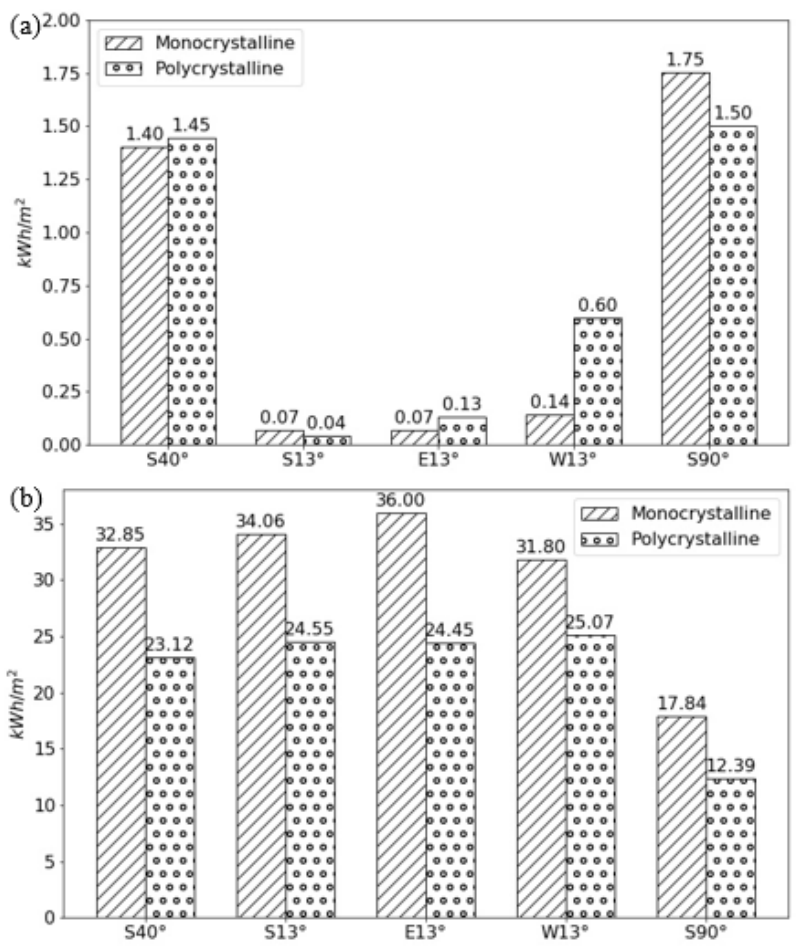

Fig. 4. Comparison of the generated energy for PC and MC panels in (a) January and (b) June 2019.

Table 2. Energy generated by MC and PC panels over a year depending on their orientation

\begin{tabular}{|l|l|l|l|l|l|}
\hline Orientation & S40 & S13 & E13 & W13 & S90 \\
\hline Relation & 1,35 & 1,34 & 1,40 & 1,24 & 1,32 \\
\hline
\end{tabular}

Measurement results also allow to assess the actual efficiency by using the radiation intensity measured for a horizontal surface as a reference (Figure 2b). Of course, efficiency depends on panel specifications, the temperature regime and other factors. PC panel efficiency decreases by $12-14 \%$ in June and July and is twice lower than in winter months. This is most likely due to panel overheating which reduces efficiency (Figure 5). The efficiency of MC panels in June is 17$19 \%$. This indicates that they are less susceptible to 
overheating which agrees with panel specifications. Average efficiency over a year (PV generated versus total solar energy) for $40^{\circ}$ and $13^{\circ}$ panel orientations is up to $21 \%$ for $\mathrm{MC}$ and up to $16 \%$. This means that the actual efficiency in Latvian conditions is relatively close to the values expected in standardized conditions. However, users should consider that there are also transformer, transmission and storage losses, which are not accounted for in this manuscript.

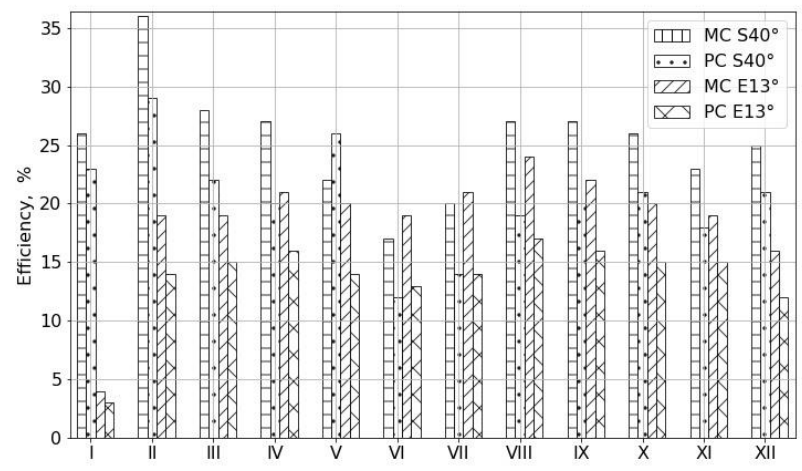

Fig. 5. Solar panel efficiency by month.

\section{Conclusions}

The first year of monitoring of various panel types and orientations in Latvian climate indicated that the difference in energy efficiency and the amount of generated energy due to "reasonable" variations of orientation does not exceed 20\%. However, MC panels can produce up to $40 \%$ more energy than PC panels with identical orientation. The actual efficiency indicators for panels correlate well with the values that were determined for standard conditions, but the energy yield in winter months is insignificant - less than $10 \%$ total. To account for the impact of cloudiness on the solar radiation intensity over different years, further monitoring is planned. Energy losses in the system and financial aspects will also be addressed so that the results can later be generalized.

This study was conducted with the financial support of European Regional Development Fund, as part of the project "Development, optimization and sustainability evaluation of smart solutions for nearly zero energy buildings in real climate conditions" (1.1.1.1/16/A/192).

\section{References}

[1] U. Sbci, Build. Clim. Chang. Summ. Decis. 1 (2009).

[2] H. Ozturk, D. Kaya, Electricity Generation from Solar Energy: Photovoltaic Technology, Umuttepe Publications, Turkey (2013)

[3] T. Dalla Mora, F. Cappelletti, F. Peron, P. Romagnoni, and F. Bauman, Energy Procedia 78, 1359 (2015).
[4] İ. Ceylan, A. Gürel, H. Demircan, and B. Aksu, Energy Build. 72, 96 (2014).

[5] C. F. Gabra, A. Hossam-Eldin, and P. D. E. Ali Ahmed Hamza H., A Comparative Analysis Between the Performances of Monocrystalline,Polycrystalline and Amorphous Thin Film in Different Temperatures at Different Locations in Egypt (2014).

[6] Latvijas vides geologiskais un metrologiskais centrs. (2019).Riga station. [database]. Retrived from https://www.meteo.lv/meteorologija-datu-meklesana/

[7] K.-F. Dagestad and J. Olseth, Sol. Energy - Sol. ENERG 81, 280 (2007).

[8] M. Boxwell ,Solar Electricity Handbook Edition 2019,(2019)

[9] K. Berzina, I. Zicmane, and K. Kasperuks, Int. J. Photoenergy 2019, 1 (2019).

[10] L. Rozentale, D. Lauka, and D. Blumberga, Energy Procedia 147, 600 (2018).

[11] JA Solar module JAP60-275/4BB data sheet. Viewed: 2020-01-09.JASolar.2016

[12] LG NeON R solar module LG365Q1C-A5 data sheet. Viewed: 2020-01-09. LGElectronics.2018 